\title{
Atividade Antifúngica de Óleos de Sementes de Frutas Frente Aos Fungos Cladosporium e Colletrotrichum
}

Manoel De Jesus Marques Da Silva (I), Poliana Brito De Sousa (li), Alexandra Brito De Sousa (I), Brennda De Sousa Meneses (I), Ana Carla Rodrigues Barbosa (I), Maria Fernanda De Freitas Bezerra (I)

(I) IFPI - Teresina - Instituto Federal do Piauí - Campus Teresina Central (Praça da Liberdade, N 1597, Centro, Teresina, Piauí.), (II) IFPI - Campus Urucui - Instituto Federal do Piauí - Campus Uruçuí (Rodovia PI 247 km 7 s/n, zona rural, Portal dos Cerrados, Uruçuí - PI.)

\section{Resumo}

A busca por produtos naturais que tem a capacidade de inibir o crescimento micelial de fitopatógenos tem se intensificado consideravelmente nos últimos anos, haja visto que os produtos de origem sintética apresentam um custo mais elevado e também agridem a saúde humana e ao meio ambiente. Fitopatógenos do gênero Colletotrichum têm sido relatados como parasitas de mais de uma centena de angiospermas. Objetivou-se com esta pesquisa verificar o efeito dos óleos obtidos de sementes de maracujá, melão, mamão e melancia, sobre o crescimento micelial de Cladoporium cladosporioides e Colletotrichum lindemuthianum. Os óleos foram obtidos das sementes dos respectivos frutos, por prensagem a frio e acondicionados em recipientes de vidro previamente higienizados. A ação fungitóxica dos respectivos óleos foi avaliada sobre a inibição do crescimento micelial dos fitopatógenos de linhagens oriundas do Centro de Ciências Agrárias da Universidade Federal do Piauí-UFPI. O meio empregado foi o BDA (Agar batata dextrose), preparado conforme determinações do fabricante. Os óleos foram adicionados ao meio ainda fundente, nas concentrações de 2; 5 e $10 \mathrm{mg}$ de óleo por $\mathrm{mL}$ do meio de cultura. Após a solidificação do meio, um disco com micélio de $6 \mathrm{~mm}$ foi transferido de uma cultura pura de 7 dias para as placas de petri contendo BDA. Após cinco dias de incubação a 
$25^{\circ} \mathrm{C}$ em estufa, procedeu-se a avaliação, que foi realizada através de medições diametrais nas colônias, quando o controle (BDA sem óleo), atingiu o máximo crescimento. Foi verificado que quanto maior a concentração dos oleos ( $2 ; 5$ e 10) de maracujá, mamão, melão e melancia, maior foi a taxa de inibição dos fungos estudados. Quanto maior as concentrações dos oleos $(2 ; 5$ e 10) menor foi o crescimento micelial. Concluiu-se que o óleo extraído das sementes de melancia apresentou o maior potencial de inibição frente aos fungos Cladoporium cladosporioides com $94,08 \%$ e sobre o Colletotrichum lindemuthianum com $81,20 \%$; O óleo de semente de maracujá foi o que apresentou menor potencial de inibição sobre os dois fungos com valores de $48,52 \%$ e $36,80 \%$, respectivamente.

Palavras-Chave: fungos, sementes, micelial Agência de Fomento: 